\section{Professional societies still at sea}

\section{Washington}

DESPITE the attention given in recent years to restrictions imposed by the US Department of Defense (DoD) on foreigners' access to technical meetings, professional societies still differ widely in their policies on the sponsorship of closed or restricted sessions.

According to the committee on scientific freedom and responsibility of the American Association for the Advancement of Science (AAAS), many societies apparently deal with DoD in an ad hoc fashion. Fewer than half of 45 technical societies affiliated to AAAS that responded to a questionnaire have adopted policies dealing with the question, but those that have generally favour prohibiting restricted-access sessions.

Government policy on open communication has been subject to several revisions in recent years. Recently, controversy has focused not so much on security classification as on export controls used to prevent access by foreigners to unclassified research results. Last October, the White House issued a security directive stating that the administration intended to use only security classification to control access to fundamental research data, to the general approval of the research community. But the imposition of export controls on meeting sessions for limiting access to applied research remains contentious.

Several important scientific societies, including the Institute of Electrical and Electronic Engineers (IEEE), have said they will not sponsor such sessions under any circumstances. Foreigners sometimes voice the suspicion that such controls are imposed more to give US industries a competitive advantage than to protect national security.

The 45 affiliated societies responding to the questionnaire were selected for their interest in subjects likely to be militarily important. Forty per cent had adopted policies on restricted sessions, almost half of them within the past five years; twothirds of those with explicit policies restricted or closed meetings. The report concludes that if more societies were to adopt formal policies, these would probably prohibit closed sessions.

A total of four societies had actually experienced "problems" with access by foreign participants in the past three years, one of them more than five times. A separate survey of 24 technical societies not affiliated with AAAS drew only 8 responses; 5 of these societies had experienced problems with access by foreigners to meetings. The AAAS report suggests that the response rate of the nonaffiliated societies was poor because the subject is politically sensitive.

DoD's most recent proposal on the subject was in a Federal Register notice on 12 February (p.5210). DoD responded to professional societies' concern by undertaking to complete security reviews of the research it sponsored in not more than 30 days, except in "rare and exceptional" cases. DoD also informally undertook in meetings organized by IEEE to ensure that security reviews would be conducted by scientifically qualified personnel, rather than by security inspectors who would "see one key word on a page and classify the whole thing", according to one IEEE negotiator.

The February statement did, however, stir already muddy waters by appearing to contradict the October White House

\section{Ethiopia}

\section{Addis Ababa}

IT is now raining in Ethiopia, and much of the country has turned green as a variety of arable crops and pasture have begun to grow again. But this has not chased away the general belief that Africa is a continent in crisis. Dr Mostafa Tolba, executive director of the United Nations Environment Programme (UNEP) based in Nairobi, Kenya, is planning to use the special meeting of the United Nations in New York from 27 to 31 May as a chance to emphasize that the current problems of Africa stem from the underlying deterioration of the African environment.

In Ethiopia, the drought and subsequent famine of 1984-85 has been the focus of attention, but the underlying question is why the ill-effects of the drought were so serious. There were at least eight serious droughts earlier this century, but none of them had such disastrous consequences.

The rapidly expanding population concentrated in the highlands of the east is one of the most conspicuous problems. The traditional pattern of settlement is that of a regular distribution of homesteads across the cultivated areas, but the density is now so high that the marginal land on the steep slopes of the mountains and precipitous river gorges has also been cleared and settled.

One consequence is that the loss of traditionally dense forest to firewood and building lumber has been enormous. In twenty years, the proportion of wooded land has fallen from 16 per cent to about 3 per cent. The result is increased erosion of the soil whose capacity for water retention is itself reduced. At the same time, UNEP officials say, the productivity and drought directive on fundamental research, declaring that DoD policy is to allow the publication of unclassified fundamental research only "to the maximum extent possible". But the October security directive definitely still stands, according to Leo Young, director of research and laboratory management in the Pentagon's office of research and advanced technology.

Young said his office had erred in not making this clear in the February statement, but, he said, the great majority of responses from societies to the proposed policy had been favourable. Young said he hoped societies could avoid holding export controlled sessions, but that some, such as the Society of Photo-optical Instrumentation Engineers, were likely always to be in sensitive areas, and that it was up to them whether or not to restrict sessions at their meetings by the use of the export controls.

\title{
Brief respite from famine
}

resistance of the land is falling, which puts pressure on subsistence farming especially when the preferred crop (teff) is lower yielding, less drought-resistant and requires more work than near-equivalents such as millet.

The vulnerability of the land to drought is made worse by poor communications and the preoccupation of the government with rebellions in at least three regions. Referred to as "structural problems" by Commissioner Tadesse of the Government Relief and Rehabilitation Commission, their significance is not underestimated. But the continuing internal conflicts make the outcome for the next drought look bleak.

Similar environmental problems in other African countries led governments to attend the first African Environment Conference, organized by UNEP, the Organization for African Unity and the Economic Commission on Africa, held last December. The outcome has been an increased awareness of the seriousness of environmental deterioration and a strong commitment to cooperation in obtaining the best possible assessment of problems such as desertification and water use to provide a reliable basis for appropriate development.

Although the piles of wheelbarrows now accumulating in the distribution centre of the aid agency, Worldvision, in Wallo region attest to the changing emphasis as the current crisis passes, any major reversal in the trend of environmental deterioration will require an awareness at all levels of the importance of the problems and the enormous collaborative effort required to tackle them.

Nigel Williams 